\title{
EFFECT OF SITE LOCATION AND COLLECTING PERIOD ON THE CHEMICAL COMPOSITION OF HYPTIS SPICIGERA Lam. AN INSECTICIDAL ESSENTIAL OIL FROM NORTH-CAMEROON
}

Félicité Noudjou ${ }^{1,3}$, Habiba Kouninki ${ }^{2,3}$, Léonard S. T. Ngamo ${ }^{3}$, Pierre M. Maponmestsem³ Martin Ngassoum ${ }^{3}$, Thierry Hance ${ }^{2}$, Eric Haubruge ${ }^{1}$, François Malaisse ${ }^{1}$, Michel Marlier ${ }^{1}$ and Georges C. Lognay ${ }^{1 *}$ email:lognay.g@ fsagx.ac.be

${ }^{1}$ Faculté Universitaire des Sciences Agronomiques, Passage des Déportés, 2, B-5030 Gembloux, Belgique

${ }^{2}$ Université Catholique de Louvain-la-Neuve, 4-5 place Croix du Sud, 1348, Louvain-laNeuve, Belgique

${ }^{3}$ Université de Ngaoundéré, BP 455, Ngaoundéré, Cameroon

* Address for correspondence 
ABSTRACT: Hyptis spicigera essential oil from seven localities in the North-Cameroon (Ngaoundere, Guirvidig, Kodeck, Lara, Toloum, Kaele, Tchecal-baila) was investigated by GC and GC/MS. Results showed differences within harvesting sites and between the different sites of collection but did not revealed clear tendencies in the evolution of essential oil composition as regard the sampling period. The main group of compounds in all the analyzed samples were: $\alpha$-pinene $(11.9 \%-42.1 \%), \beta$-pinene + sabinene $(6.0 \%-39.8 \%)$ and $\beta$ phellandrene $+1,8$-cineole $(8.8 \%-27.4 \%)$ except in one oil where $\beta$-caryophyllene $(23.4 \%)$ was the principal component. The insecticidal activity of $H$. spicigera and its principal terpenic components was evaluated against the cowpea weevil Callosobruchus maculatus F., the major cause of damages of cowpea (Vigna unguiculata (L.) Walp) in North Cameroon..

Key words: Hyptis spicigera, Lamiaceae, Essential oil composition, $\alpha$-pinene, $\alpha$-phellandrene, $\beta$-caryophyllene, Insecticidal activity.

\section{INTRODUCTION}

Hyptis spicigera Lam. (Lamiaceae) is a strong aromatic, herbaceous annual plant of 0.5 to $1 \mathrm{~m}$ high with vertical ramifications. Leaves are simple, opposite with 7 to $10 \mathrm{~cm}$ long and 1 to 3 $\mathrm{cm}$ wide. Inflorescences are very small and are assembled in terminal dense ears of 2 to $10 \mathrm{~cm}$ long (1). Fruits contain each one seed. Although endemic to Brazil, it is widespread in tropical Africa and in Asia where it grows naturally on road sides and on cultivated lands.

Hyptis spicigera is traditionally used as a drug, insecticide and even as a foodstuff (2). Infusions prepared with leaves are used against cough, bronchitis and headaches (11). Soaps, lotions, and perfumes made from the flowers, by people of northern Nigeria, are part of baths 
or decoctions for the treatment of various skin diseases (2). In Central and eastern Africa, and also in Guinea, $H$. spicigera is cultivated and the oleaginous seeds are eaten like sesame. It is also recognized as a valuable bio-pesticide, because when mixed with grains $(3 \mathrm{~g}$ of dried leaves powder for $1 \mathrm{~kg}$ of grains), $H$. spicigera exhibits strong insecticidal and repellent activities against insects devastating stored grains (3). Within a large ethnobotanical survey carried out in northern Cameroon, Ngamo and Mapongmetsem (personal communication, 2004) highlighted that $H$. spicigera is traditionally used by some ethnic groups (Guiziga, Massa, Mofu, Musgum, Mundang...) to protect cowpeas and sorghum against insects infestation. The insecticidal potentiality of $H$. spicigera has been emphasized by some authors (3, 4). Lambert et al. (3) managed to control the oviposition and the hatching of weevils by treatment of peas with alcoholic extracts of $H$. spicigera. Niber (4) showed the efficiency of slurries, made with leaves of $H$. spicigera and distilled water, against two major pests: Prostephanus truncatus Horn (Coleoptera: Bostrichidae) and Sitophilus oryzea L (Coleoptera: Curculionidae).

There are not many data on the phytochemical characterization of $H$. spicigera. However, seven new labdanes were isolated and structurally characterized (5). One of these natural compounds $\quad(15,19$-diacetoxy-2 $\alpha, 7 \alpha$-dihydroxylabda- $8(17), 13(\mathrm{Z})$-diene $) \quad$ significantly inhibited the larval growth of the european corn borer (Ostrinia nubilalis Hübner Lepidoptera: Pyralidae) (5). A spicigera $\delta$-lactone (5,6-diacetoxy-1,2-epoxy-1,5' (2'-pentane-5'-olide)-3Eheptene) was isolated from the inflorescences of $H$. spicigera (6).

The chemical composition of $H$. spicigera essential oil published (7-12) suggests the existence of a $\beta$-Caryophyllene chemotype. It's found as major compound in oils from Burkina Faso (7) (57.3-65.7\%), Nigeria (8) (67.6\%) and Mali (9) in lower content (23.527.2\%). Other compositions have also been reported (10) with $\alpha$-pinene (43\%) and $\beta$-pinene (15\%) as main compounds. In Cameroon, Jirovetz et al. (11) found terpinolene (15.01$27.47 \%)$, sabinene (19.69-20.27\%) and $\alpha$-thujene (11.51-12.49\%) as main compounds, 
whereas Tchoumbougnang et al. (12) reported $\alpha$-pinene $27.3 \%, \beta$-caryophyllene $20.1 \%$, limonene $13.4 \%$ and $\beta$-pinene $10.3 \%$.

These papers dealing with the chemical composition of $H$. spicigera essential oil have been published on the basis of the analyses of selected samples from restricted harvesting sites. Therefore, it is noteworthy that no data are available on the effect of geographical location and sampling period on the essential oil composition. Information of this kind is very important when a standardized application of $H$. spicigera as bio-pesticide is of practical concern. Therefore the main target of the present work was to evaluate the variability of essential oil compositions in function of their origin and collecting period. The second part of the work has been designed to better understand the bio-pesticide properties of $H$. spicigera volatile compounds. The activities of the whole essential oil as well as its pure (commercially available) components alone or blended in proportions reflecting those reported for the natural extract has been measured against the cowpea weevil Callosobruchus maculatus $\mathrm{F}$., the major cause of damages of cowpea (Vigna unguiculata (L.) Walp) in North Cameroon. The present study takes part of an ongoing research focusing on the use of local natural insecticides to limit damages to granaries stored products.

\section{EXPERIMENTAL}

Plant material: Dried flowers of $H$. spicigera were collected in seven loacilities of Northern Cameroon: Ngaoundere (H0), Guirvidig (H1), Kodeck (H2), Lara (H3), Toloum (H4), Kaele (H5) and Tchecal-baila (H6) (Figure1). Plant collection took place in May (at the beginning of the rainy season) and in January (during the dry season), except for H0 which was collected only in May. Voucher specimens were deposited at the National Herbarium of Yaounde (Voucher No. 70754/HNC). 
Pure $\alpha$-pinene, $\beta$-pinene, $\alpha$-phellandrene and 1,8-cineole (GC purity $\geq 98 \%$ ) were purchased from Sigma-Aldrich (Belgium)

Isolation of essential oil: Plant samples $(50 \mathrm{~g})$ were subjected to hydrodistillation for 3 hours using a Clevenger-type apparatus to produce pale yellow oils which were dried with anhydrous sodium sulphate and stored in sealed vials at $4^{\circ} \mathrm{C}$ before use. To undertake repeated bio-tests directed towards measuring the toxicity of $H$. spicigera oil, larger quantities of plants (H0) were collected during the dry season at Ngaoundere.

Chromatographic analysis: The analysis were performed using an Agilent (HP-6890) gas chromatograph fitted with a fused silica capillary column $(30 \mathrm{x} 0.25 ; 0.25 \mu \mathrm{m}$ film thickness, coated with a 5\% phenyl 95\% dimethylpolysiloxane stationary phase HP-5 from Agilent) and a split/splitless injector (splitless mode) at $250^{\circ} \mathrm{C}$. The oven temperature was programmed from $40-210^{\circ} \mathrm{C}$ at $5^{\circ} \mathrm{C} / \mathrm{min}$, and from $210-280^{\circ} \mathrm{C}$ at $30^{\circ} \mathrm{C} / \mathrm{min}$, with a final hold of $5 \mathrm{~min}$ at $280^{\circ} \mathrm{C}$. Helium was the carrier gas at $1 \mathrm{ml} / \mathrm{min}$, and the FID detector was maintained at $280^{\circ} \mathrm{C}$. The relative amount of individual components was calculated based upon gas chromatographic peak areas with a common correction factor of one. All the samples were analyzed by GC/MS (Agilent 6890 GC coupled to an Agilent 5973 mass spectrometer) using the same analytical conditions. The mass spectra were recorder in the EI mode at $70 \mathrm{eV}$, scan mass range from 35 to $350 \mathrm{amu}$, source temperature: $230^{\circ} \mathrm{C}$.

Identification of the oil components was undertaken by comparing fragmentation patterns and retention indices with those of the WILEY 275.L , Adams (13) and Joulain and König (14) databases .

Insecticidal activity: Cowpea weevils (Callosobruchus. Maculatus F.) from Cameroon were reared in cowpea seed at $28^{\circ} \mathrm{C}, \mathrm{R} . \mathrm{H}=65 \%$. Newly emerged adults of two days old were used to assess the test. The activity of the oil and the four major compounds against $C$. maculatus was measured in closed glass dessicators of $800 \mathrm{~mL}$. To avoid contact between insects and the tested products, twenty-five C. maculatus were transferred to perforated petri dishes and 200 
$\mu \mathrm{L}$ of essential oil of $H$. spicigera (which represents $215 \mu \mathrm{g}$ oil/ litre of air); or its equivalent concentrations of $\alpha$-pinene, $\beta$-pinene, $\alpha$-phellandrene and 1,8-cineole (alone or in combination), were deposited in glass petri dishes at the bottom of the dessicator. The control consisted of a similar set up but without any added product. Each experiment was replicated five times with 25 insects and the observed mortality (fumigant activity) was measured after 24hours. The recorded values were analysed after transformation with arcsine square root by one way ANOVA. Treatment means of untransformed data were compared and separated by Duncan's test at $\mathrm{P}<0.05$.

\section{RESULTS AND DISCUSSION}

Essential oil yields varied from 0.1 to $0.4 \%$, and regardless of the origin they were higher during the dry season (January) than at the beginning of the rainy season (May). These results are in line with those of the literature $(8,9)$. Differences were also noticed in oil composition between the sample origin and within samples from the same site (Table I). A total of 44 components have been identified. Excepted in H1 (Guirvidig sample collected in May), monoterpenes hydrocarbons represent the principal class of molecules with five main components: $\alpha$-pinene $(11.9 \%-42.1 \%), \quad \beta$-pinene + sabinene $(6.0 \%-39.8 \%)$ and $\beta$ phellandrene $+1,8$-cineole $(8.8 \%-27.4 \%)$. In the aforementioned analytical conditions these two pairs of molecules co-eluted, the later being not separated from limonene. Although this product has already been reported in oil sample from Mali (9) (percentages ranging from $1.7 \%$ to $3.0 \%)$ and in a former study (11) of $H$. spicigera dried flowers from Cameroon (4.87.6\%), careful examination of the reconstructed ion chromatograms (RIC on both Molecular ion and $\mathrm{m} / \mathrm{z}=68$ characteristic of limonene fragmentation) of each compound with a retention index (RI) ca. 1028 revealed only traces of this molecule excepted in H6 collected in the dry season. Using similar analytical conditions, Tchoumbougang et al. (12) reported a limonene percentage of $13.4 \%$ in a batch of $H$. spicigera harvested in Garoua. It seems unlikely to 
discriminate between the three co-eluted molecules (RI ca. 1028) therefore, limonene, $\beta$ phellandrene and 1,8-cineole were not integrated as separate components. In H1 sample (collected in May), $\beta$-Caryophyllene (23.4\%) predominated and it was found as the main sesquiterpene hydrocarbon in all the examined samples. Similar proportions have been previously reported (12). $\beta$-Caryophyllene has also been mentioned as the major compound in H. spicigera oil from Burkina Faso (7), Nigeria (8) and Mali (9) where it attained much higher levels ( $23.5 \%-27.2 \%, 68 \%$ and $62.7 \%$, respectively). From the present study and the literature survey, it should be assumed that chemotypes exist. Nevertheless only systematic and repeated investigations could support this assumption.

From Table I, it did not appear a clear general tendency in the evolution of essential oil composition as regard the sampling period but for some components large differences have been detected: particular increases of $\alpha$-terpinolene in $\mathrm{H} 2$ (0.4 to 15.2$)$ and $\mathrm{H} 6$ (2.2\% to $17.7 \%)$; $\alpha$-phellandrene in $\mathrm{H} 1$ (4.0\% to $22.5 \%)$, $\alpha$-pinene in $\mathrm{H} 3$ (19.8\% to $42.1 \%$ ) have been observed but still remain un-interpretable. Geographic variability (most likely linked to climatic factors) has been revealed between the different harvesting sites. In all the analyzed samples, 1,8-cineole was the major oxygenated monoterpenes and caryophyllene oxide was the main oxygenated sesquiterpenes specially in H1 (from May) were it represented $10.9 \%$. All other oxygenated compounds have been detected in proportions less than $1 \%$. Most of the non identified molecules were detected in low percentages $(<0.1 \%)$ and hardly discernible on the basis of the recorded total ion current. The recording of interpretable mass spectra was impossible for most of them.

Insecticidal trials were performed with the H0 sample of $H$. spicigera from Ngaoundéré. For that purpose repeated hydrodistillations have been performed in order to obtain the required quantities of oil. The main compounds of the pooled oils represented $90.3 \%$ of the total oil compounds and were identified as $\alpha$-pinene (39.0\%), 1,8- cineole $+\beta$-phellandrene $(23.5 \%), \beta$-pinene + sabinene $(14.6 \%)$ and $\alpha$-phellandrene (13.2\%), respectively. 
The fumigant activities of $H$. spicigera and its principal terpenic components (only $\alpha$-pinene, 1,8- cineole, $\beta$-pinene and $\alpha$-phellandrene were considered because they were available in pure form) are summarized in Table II. When compared to H. spicigera oil (mortalities of $100 \%$ and $99.2 \%$, respectively for the two series), the corresponding concentrations of pure chemicals induced variable effects which indicated a structure-concentration - activity relationship. Indeed $\alpha$-pinene was found to be the more active molecule whereas 1,8- cineole, $\beta$-pinene and $\alpha$-phellandrene led to limited mortalities ranging from $48.8 \%$ to $24.8 \%$, respectively. Nevertheless synergistic effects were systematically observed when $C$. maculatus was exposed to terpenes blends made on the basis of oil composition of H0. All the combinations used led to a similar "knock down" effect with very high mortality levels (> 90\%) except the 1,8 - cineole $+\alpha$-phellandrene mixture which was significantly different. At this step of the work, the enantiomeric excess of the different chiral molecules has not bee determined. However, it would be valuable in further studies, to perform chiral chromatography in order to establish whether some particular isomers are driving the activity.

\section{CONCLUSION}

The present observations confirm the strong bio-pesticide properties of $H$. spicigera oil and evaluate the effect of some its major monoterpenes. To the authors knowledge there are no previous reports on the determination of the chemical compounds responsible of the fumigant activity of $H$. spicigera oil. Although the selected compounds have a significant biocide activity, it is noteworthy that the other components could also contribute to the properties of the oil.

Moreover, taking into account both the composition of the sample $\mathrm{H} 0$ oil and the biocidal properties of the tested pure molecules, more extensive studies need to be performed, in particular for samples H3 and H5. Such studies are in progress as well as the evaluation of the phenologic stage of the plant on essential oil composition and properties. This work 
constitutes the background of an integrated pest management approach by using simple formulations of $H$. spicigera oils. It also shows that the variability in oil composition is large and has to be considered in practical future developments.

\section{Acknowledgments}

The authors gratefully acknowledge the Belgian University Cooperation to Development organisation (CUD: Commission Universitaire pour le Developpement) for financial support through "STOREPROTECT" project. 


\section{REFERENCES}

1. T. Le Bourgeois and H. Merlier, Adventrop. Les adventices d'Afrique soudanosahélienne. Ed. CIRAD-CA, Montpellier, France (1995).

2. P. Golob, C. Moss, M. Dales, A. Fidgen, J. Evans and I. Gudrups, The use of spices and medicinals as bioactive protectants for grains. FAO Agricultural Services Bulletin, 137 (1999).

3. H. D. Lambert, J. Gale, J. T. Arnason and R. J. B. Philogene, Bruchid control with traditionally used insecticidal plants Hysptis spicigera and Cassia nigricans. Insect. Sci. Applic., 6, 167-170 (1985).

4. B. T. Niber, The ability of powders and slurries from ten plant species to protect stored grain from attack by Prostephanus truncatus Horn (Coleoptera: Bostrichidae) and Sithophillus oryzae L. (Coleoptera: Curculioniadae). J. StoredProd. Res., 30, 297301 (1994).

5. M. Fragoso-Serrano, E. Gonzólez-Chimeo and R. Pereda-Miranda, Novel Labdanes diterpenes from the insecticidal plant Hyptis spicigera. J. Nat. Prod., 62, 45-50 (1999).

6. J. P. Aycard, F. Kini, B. Kam, E.M. Gaydou and R. Faure, Isolation and Identification of Spicigera Lactone: Complete ${ }^{1} \mathrm{H}$ and ${ }^{13} \mathrm{C}$ Assignments Using Two-Dimensional NMR Experiments. J. Nat. Prod., 56, 1171-1173 (1993).

7. F. Kini, B. Kam, J. P. Aycard, E. M. Gaydou and I. Bombarda, Chemical composition of essential oil of Hyptis spicigera Lam. From Burkina Faso. J. Essent. Oil Res., 5, 219-221 (1993).

8. O. A. Onayade, A. Looman, J. J. C. Scheffer and A. Baerheim. Svendsen, Composition of the herb essential oil Hyptis spicigera Lam. Flav. Fragr J., 5, 101-105 (1990). 
9. L. Sidibe, J. C. Chalchat and R. P. Garry, Aromatic plants of Mali (III): chemical composition of essential oils of two Hyptis species: H. suaveolens (L.) Poit. And H. spicigera Lam. J. Essent. Oil Res., 13, 55-57 (2001).

10. A. Belanger, L. Dextraze, M. Nacro, A. D. Samaté, G. Collin, E. X. Garneau and H. Gagnon, Compositions chimiques d'huiles essentielles de plantes aromatiques du Burkina Faso. Acte des 13èmes journées internationales huiles essentielles, DigneLes-Bains, France, 300-305 (1994)

11. L. Jirovetz, G. Buchbauer, C. Puschmann and M. B. Ngassoum, Investigations of aromatic plants from Cameroon: Analysis of the essentials oils of flowers of Hyptis spicigera (Linn.) Poit. By GC, GC/MS and olfactometry. J. Essent Oil Bear Plants, 3, 71-77 (2000).

12. F. Tchoumbougang, P. H. Amvam Zollo, F. Fekam Boyom, M. A. Nyegue and J. M. Bessière, Aromatic plants of tropical Central Africa. XLVIII. Comparative study of the essential oils of four Hyptis species from Cameroon: H. lanceolata Poit., H. pectinata (L.) Poit., H. spicigera Lam. and H. suaveolens Poit. Flav. Fragr J., 20, 340-343 (2005)

13. R. P. Adams, Identification of essential oil components by gas chromatography/quadrupole mass spectroscopy. Allured Publishing Corporation, Carol Stream IL. (2001).

14. D. Joulain and W. A. König, The Atlas of Spectral Data of Sesquiterpene Hydrocarbonss. Hamburg, EB-Verl., Germany (1998).

15. H. S. Prates, J. P. Santos, J. M. Waquil, A. B. Olivera and J. E. Foster, Insecticidal activity of monoterpenes against Rhizopertha dominica $(F)$ and Tribolium castaneum (Herbst). J. Stored Prod Res., 34, 243-249 (1998)

16. I. K. Park, S. G. Lee, D. W. Choi, J. D. Park and Y. J. Ahn, Insecticidal activities of constituents identified in the essential oil from leaves of Chamaecyparis obtusa 
against Callosobruchus Chinensis (L.) and Sitophilus oryzae (L.). J. Stored Prod Res., 39, 375-384 (2003). 
Table I. Essential oil composition (\%) of Hyptis spicigera from North-Cameroon

\begin{tabular}{|c|c|c|c|c|c|c|c|c|c|c|c|c|c|c|}
\hline & \multirow[t]{2}{*}{ KI } & \multirow{2}{*}{$\begin{array}{c}\mathrm{H} 0 \\
\text { Jan* }\end{array}$} & \multicolumn{2}{|c|}{ H1 } & \multicolumn{2}{|c|}{$\mathrm{H} 2$} & \multicolumn{2}{|c|}{$\mathrm{H} 3$} & \multicolumn{2}{|c|}{$\mathrm{H} 4$} & \multicolumn{2}{|c|}{ H5 } & \multicolumn{2}{|c|}{ H6 } \\
\hline & & & May & Jan* & May & Jan* & May & Jan* & May & Jan* & May & Jan* & May & Jan* \\
\hline yield (\%) & & 0.4 & 0.1 & 0.3 & 0.2 & 0.3 & 0.1 & 0.2 & 0.2 & 0.3 & 0.2 & 0.3 & 0.2 & 0.3 \\
\hline$\alpha$-thujene & 923 & 0.2 & - &  & "0.4 & "0.4 & 1.1 & 2.2 & 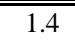 & "0.4 & 3.1 & "0.5 & "0.1 & 10.7 \\
\hline$\alpha$-pinene & 930 & 39.0 & 14.0 & 27.1 & 36.3 & 39.6 & 19.8 & 42.1 & 31.7 & 23.8 & 20.6 & 34.8 & 27.8 & 11.9 \\
\hline camphene & 943 & - & - & 0.1 & - & 0.2 & 0.4 & 0.2 & 0.7 & 0.1 & 0.5 & 0.2 & 0.6 & 0.1 \\
\hline verbenene & 949 & - & - & - & - & - & 0.3 & - & 0.3 & - & 0.3 & - & 0.3 & - \\
\hline sabinene $+\beta$-pinene & 973 & 14.6 & 6.0 & 9.4 & 14.1 & 15.1 & 13.1 & 22.7 & 16.1 & 10.7 & 17.6 & 17.0 & 10.9 & 39.8 \\
\hline myrcene & 987 & - & & & & 0.6 & 0.2 & 0.7 & 0.2 & 0.1 & 0.2 & 0.3 & 0.2 & 1.1 \\
\hline$\alpha$-phellandrene & 1004 & 13.2 & 4.0 & 22.5 & 7.8 & 1.9 & 0.3 & 4.4 & 6.7 & 14.2 & 3.0 & 0.2 & 1.3 & 0.3 \\
\hline$\alpha$-terpinene & 1014 & 0.4 & 0.2 & 0.1 & 0.4 & & 0.4 & 0.0 & 0.4 & 0.1 & 0.8 & & 0.1 & - \\
\hline p-cymene & 1023 & 1.3 & 2.6 & 0.1 & 3.0 & 0.1 & 1.2 & 0.1 & 3.1 & 0.1 & 3.0 & 0.1 & 2.0 & 0.5 \\
\hline$\beta$-phellandrene $+1,8$-cineole & 1028 & 23.5 & 14.8 & 20.9 & 23.2 & 14.7 & 27.4 & 13.7 & 23.7 & 20.5 & 23.5 & 19.4 & 21.3 & 8.8 \\
\hline$\gamma$-terpinene & 1056 & 0.3 & & 0.2 & 0.4 & 0.3 & 1.2 & 0.6 & 0.8 & 0.2 & 1.7 & 0.3 & 0.1 & 1.2 \\
\hline terpinolene & 1086 & 0.3 & 0.3 & 0.9 & 0.4 & 15.2 & 1.9 & 4.5 & 1.1 & 3.2 & 2.3 & 2.1 & 2.2 & 17.7 \\
\hline linalool & 1098 & - & - & - & - & 0.2 & - & - & 0.7 & 0.6 & 0.2 & 0.6 & 0.3 & - \\
\hline isoamyl isovalerate & 1102 & - & 2.0 & 1.2 & 0.3 & 0.6 & 0.9 & 0.6 & 0.5 & 0.8 & 1.1 & 0.8 & 1.1 & 0.8 \\
\hline$\beta$-thujone & 1120 & - & - & - & - & - & - & - & 0.1 & - & 0.3 & - & - & - \\
\hline$\alpha$-campholenal & 1124 & 0.1 & 0.2 & 0.1 & - & 0.2 & 0.7 & 0.1 & 0.2 & 0.2 & 0.5 & 0.4 & 0.4 & 0.1 \\
\hline nopinone & 1134 & - & 0.1 & - & - & - & 0.2 & - & 0.1 & - & 0.2 & - & 0.1 & - \\
\hline cis-sabinol & 1137 & 0.3 & 1.3 & 0.1 & 0.7 & 0.5 & 1.9 & 0.1 & 0.7 & 0.8 & 1.3 & 1.0 & 1.7 & 0.7 \\
\hline$\alpha$-phellandren-8-ol & 1160 & 0.2 & 0.5 & 0.1 & 0.3 & 0.1 & 0.7 & 0.1 & 0.3 & 0.1 & 0.3 & 0.5 & 0.6 & - \\
\hline terpinen-4-ol & 1175 & 0.3 & 0.4 & - & 2.2 & 0.6 & 2.9 & 0.1 & 1.6 & 0.6 & 3.6 & - & 0.5 & 0.3 \\
\hline p-cymen-8-ol & 1182 & 0.1 & 0.6 & - & 0.8 & 0.4 & 0.8 & - & 1.6 & 0.2 & 3.7 & 0.2 & 1.2 & - \\
\hline$\alpha$-terpineol & 1188 & 0.1 & 0.3 & - & 0.3 & 0.4 & 0.6 & - & 0.2 & 0.5 & 0.3 & 0.5 & 0.3 & - \\
\hline myrtenal+myrtenol & 1190 & 0.2 & 0.7 & 0.1 & 0.6 & 0.11 & 1.3 & 0.1 & 0.5 & 0.15 & 1.0 & 0.3 & 0.9 & - \\
\hline verbenone & 1200 & 0.1 & 0.1 & - & - & - & 0.1 & - & 0.1 & - & 0.1 & - & 0.1 & - \\
\hline
\end{tabular}




\begin{tabular}{|c|c|c|c|c|c|c|c|c|c|c|c|c|c|c|}
\hline cuminaldehyde & 1234 & - & 0.4 & - & - & - & 0.2 & - & 0.1 & - & 0.3 & - & 0.2 & - \\
\hline phellandral & 1274 & - & 0.3 & - & - & - & 0.2 & - & 0.1 & - & 0.2 & - & 0.1 & - \\
\hline thymol & 1291 & - & 0.1 & - & 0.1 & - & - & - & 0.1 & - & 0.1 & - & 0.4 & - \\
\hline carvacrol & 1300 & - & 0.4 & - & - & - & 0.1 & - & & - & 0.1 & - & 0.2 & - \\
\hline$\alpha$-ylangene & 1372 & 0.2 & 0.3 & 0.1 & - & 0.1 & 0.2 & 0.1 & - & 0.2 & 0.1 & 0.2 & 0.2 & - \\
\hline$\alpha$-copaene & 1377 & - & 0.1 & - & 0.2 & 0.0 & 0.1 & 0.1 & 0.1 & 0.1 & 0.1 & 0.3 & 0.1 & 0.1 \\
\hline$\beta$-bourbonene & 1385 & - & 0.1 & - & - & - & 0.2 & - & 0.1 & - & 0.1 & - & 0.1 & - \\
\hline$\beta$-cubebene & 1392 & 0.1 & 0.2 & 0.1 & - & - & 0.1 & 0.1 & 0.1 & 0.1 & 0.1 & 0.1 & 0.1 & 0.1 \\
\hline iso-caryophyllene & 1407 & 2.2 & 0.2 & - & - & - & 0.1 & - & & 0.1 & & 0.1 & 0.1 & - \\
\hline$\beta$-caryophyllene & 1424 & - & 23.4 & 10.8 & 3.6 & 6.1 & 9.1 & 4.9 & 2.8 & 13.7 & 3.2 & 11.7 & 12.3 & 3.3 \\
\hline$\gamma$-elemene & 1434 & - & 0.2 & 0.1 & - & - & - & - & - & 0.1 & - & 0.1 & 0.1 & - \\
\hline guaia-6,9-diene & 1444 & - & 0.2 & 0.1 & - & 0.1 & 0.1 & 0.1 & - & 0.1 & - & 0.1 & 0.1 & - \\
\hline$\alpha$-humulene & 1456 & - & 1.3 & 0.6 & 0.3 & 0.3 & 0.6 & 0.3 & 0.3 & 0.7 & 0.2 & 0.6 & 0.7 & 0.2 \\
\hline germacrene $\mathrm{D}$ & 1483 & 0.1 & 0.2 & 0.2 & 0.1 & 0.1 & 0.1 & 0.2 & 0.1 & 0.2 & 0.1 & 0.2 & 0.2 & 0.1 \\
\hline bicyclosesquiphellandrene & 1490 & - & 0.1 & - & 0.1 & - & - & - & - & - & - & - & - & - \\
\hline$\gamma$-cadinene & 1516 & 0.3 & 2.2 & 0.1 & 0.6 & & 0.8 & & & 0.1 & & 0.1 & 0.8 & - \\
\hline$\delta$-cadinene & 1525 & 0.1 & 0.6 & 0.1 & 0.2 & 0.1 & 0.2 & - & 0.1 & 0.1 & 0.1 & 0.2 & 0.3 & - \\
\hline$\alpha$-cadinene & 1539 & - & 0.2 & - & - & - & 0.1 & - & - & - & - & - & - & - \\
\hline$\alpha$-calacorene & 1551 & - & 0.5 & - & - & - & - & - & - & - & 1.2 & - & 0.2 & - \\
\hline caryophyllene oxide & 1587 & - & 10.9 & 2.0 & 1.8 & 0.5 & 5.1 & 0.7 & 0.8 & 2.3 & - & 2.9 & 4.8 & 0.8 \\
\hline 1-epi-cubenol & 1629 & - & 0.3 & 0.1 & - & - & 0.2 & - & - & 0.1 & - & 0.1 & 0.1 & - \\
\hline NI compounds & & 2.1 & 9.1 & 2.3 & 1.9 & 1.6 & 5.2 & 1.4 & 2.5 & 4.7 & 5.0 & 4.4 & 4.7 & 1.2 \\
\hline
\end{tabular}

H0: Ngaoundere ; H1: Guirvidig ; H2: Kodeck ; H3: Lara ; H4: Touloum ; H5: Kaele ; H6: Tchecal-baïla

May : beginning of the rainy season

*Jan : january, dry season

NI: Non identified 